\title{
Clinical and functional evaluation of primary anterior crucial ligament reconstruction by using allograft
}

\author{
Sebastian Krupa ${ }^{1, A-F}$, Paweł Reichert ${ }^{2, A, C, E, E, F}$ \\ ${ }^{1}$ Trauma and Orthopedics Department, eMKaMED Medical Center, Wrocław, Poland \\ 2 Department of Sports Medicine, Wroclaw Medical University, Poland \\ A - research concept and design; $\mathrm{B}$ - collection and/or assembly of data; $\mathrm{C}$ - data analysis and interpretation; \\ $D$ - writing the article; $E$ - critical revision of the article; $F$ - final approval of the article
}

\section{Address for correspondence \\ Paweł Reichert}

E-mail: pawelreichert74@gmail.com

Funding sources

None declared

Conflict of interest

None declared

Received on May 18, 2020

Reviewed on May 26, 2020

Accepted on June 30,2020

Published online on September 1, 2020

\begin{abstract}
Background. The reconstruction of the anterior cruciate ligament (ACL) of the knee joint is the gold standard in complete ACL rupture treatment. One of the central discussion topics is choice of graft.

Objectives. To assess the outcome of treatment after primary ACL reconstruction using allograft.

Material and methods. The study was a retrospective cohort study. Out of 372 male patients who had undergone primary unilateral intra-articular ACL reconstruction using strict inclusion and exclusion criteria, 61 patients who qualified for the study took part. Group I was made up of 31 patients with allograft, while Group II consisted of 30 patients involved with autograft. The Lachman test, Pivot-Shift test, Lysholm Knee Scoring scale, and 2000 International Knee Documentation Committee (IKDC) were used to evaluate the results. Follow-up time was 18 months.

Results. The knee joint regained anterior stability in subjective and objective assessments in all the patients in both groups. The subjective results were the following: in Group I, $96.6 \pm 3.08$ points on the Lysholm scale and $94.79 \pm 6.53$ points on the IKDC 2000 scale, while in Group II, $98.00 \pm 1.9$ points on the Lysholm scale and $94.81 \pm 5.6$ points on the IKDC 2000 scale. The group comparison of the results of the IKDC 2000 and Lysholm Scale obtained postoperatively showed no statistically significant differences between the 2 groups.

Conclusions. Primary ACL reconstruction using an allograft is an effective procedure to counteract instability of the anterior knee joint. Comparative analysis of the results of primary ACL reconstruction in the treatment of anterior knee instability using autograft or allograft gives grounds for the possibility of individual selection of graft depending on what the patient's expectations are.
\end{abstract}

Key words: anterior cruciate ligament, allograft, autograft, ACL reconstruction, knee arthroscopy

Cite as

Krupa S, Reichert P. Clinical and functional evaluation

of primary anterior crucial ligament reconstruction

by using allograft. Adv Clin Exp Med. 2020;29(9):1029-1037.

doi:10.17219/acem/124883

DOI

10.17219/acem/124883

Copyright

Copyright by Author(s)

This is an article distributed under the terms of the

Creative Commons Attribution 3.0 Unported (CC BY 3.0)

(https://creativecommons.org/licenses/by/3.0/) 


\section{Background}

The anterior cruciate ligament (ACL) of the knee joint plays a complex and integral role in stabilizing the knee joint, and resisting anterior displacement and excessive rotation of the tibia relative to the femur. ${ }^{1}$ Reconstruction of the ACL of the knee joint ${ }^{2}$ followed by a postoperative physiotherapeutic procedure ${ }^{3}$ is the standard ACL injury treatment for individuals wishing to return to high-level sports activities. There is no gold-standard treatment option; however, for ACL reconstruction, and when choosing the technique, the surgeon's experience and numerous patient-specific factors, as well as cost and efficacy, are taken into account., ${ }^{4,5}$ Available graft options include autografts and allografts, but synthetic ligaments can also be used. The autograft choices are the patellar, hamstring and quadriceps tendons, where allografts include the quadriceps, patellar, Achilles, hamstring, anterior, and posterior tibialis tendons, and the fascia lata. ${ }^{5}$ The advantages of allografts include active complications, reduced morbidity rate at the harvest site, a more rapid postoperative recovery, lower incidence of postoperative arthrofibrosis, and lower postoperative pain. ${ }^{4,6}$ At the same time, the use of allografts may come with higher rates of rupture, limited availability, delayed healing, and ligamentization in comparison to autografts, as well as the prospect of disease transmission and high price. ${ }^{7-9}$ The synthetic materials used in ACL reconstruction are utilized to improve the strength and stability of the graft immediately after the reconstruction, reduce donor site incidence of disease and diminish the potential for disease transmission. ${ }^{1-3}$ Differences in the above factors also determine the differences in moving forward with postoperative and rehabilitation proceedings. This is applicable to the time to relieve the operated limb, the necessity and duration of using an orthosis device, the degree of limitation of mobility in the orthosis device, the duration of each stage of both supervised and unattended rehabilitation, and the time to return to work, sport and other physical activities. ${ }^{2,3}$

The objective of this study was to analyze the results of treatment after primary ACL reconstruction using allograft.

\section{Material and methods}

The study had a retrospective design. The assessment was performed in patients who had undergone ACL reconstruction at the eMKaMED Medical Center in Wrocław, Poland. The study was carried out at the Center of Rehabilitation and Medical Education according to the ethical guidelines and principles of the Declaration of Helsinki. All the participants in the present study were informed of its intent and what its approach was. The study was approved by the Bioethics Committee of the Wroclaw Medical University and written informed consent forms were signed by all of the participants prior to commencement of the study.

Patients were separated into 2 research groups. The $1^{\text {st }}$ group consisted of patients operated on using the allograft, the $2^{\text {nd }}$ group included patients operated on using the autograft. Of the 372 primary ACL reconstruction procedures performed in this period, on 55 patients an allograft procedure was implemented, which represents $14.8 \%$ of all patients. A total of 299 patients were operated on with autografts, representing $80.4 \%$. Eighteen patients (4.8\%) were operated on using synthetic ligaments.

From the group of patients who underwent primary ACL reconstruction using autografts and allografts, patients were deemed eligible for the study based on the following criteria:

Inclusion criteria: knee instability confirmed with clinical examination; age 20-50 years; magnetic resonance imaging (MRI) confirmed the complete ACL rupture; no history of previous injuries to the operated limb; 1 stage surgery performed 6-9 weeks after initial injury; surgery performed by the same surgical team using the same method and the same rehabilitation program.

Exclusion criteria: patients operated on immediately after the injury; injuries involving multiple ligaments; accompanying injuries of menisci and cartilage surfaces requiring supply during surgery.

Thirty-six patients operated on with allograft met these criteria. During the study, 4 patients stopped reporting for follow-up examinations, and 1 patient after returning to physical exertion about 14 months after ACL reconstruction surgery suffered another injury with graft rupture. Ultimately, Group I consisted of 31 patients undergoing ACL reconstruction using an allograft, including 23 men and 8 women. The average age was 37.8 years. The left knee joint was operated on in 18 cases, the right knee joint in 13 cases.

From patients who met the above criteria and were undergoing ACL reconstruction using hamstrings, a control group was selected that was demographically and statistically similar to the research group. One patient did not report for the final follow-up examination 18 months after the surgery due to being abroad.

Group II of patients with hamstrings operated on consisted of 30 patients, including 23 men and 7 women. The average age was 30.4 years. Left knee joint was operated on in 14 cases, right knee joint in 16 cases.

\section{Surgical procedures}

The arthroscopic procedure for reconstruction of the ACL was employed for all grafts. After ACL rupture was confirmed (Fig. 1), the autograft was dissected (Fig. 2,3) and drawn out (Fig. 4) or an allograft was prepared (Fig. 5).

The outside-in technique employing the transtibial technique was utilized for reconstruction. The tibial tunnel 


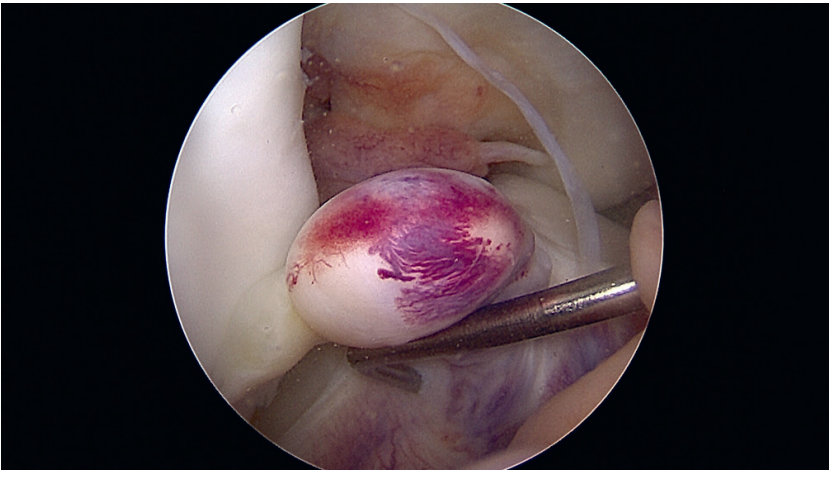

Fig. 1. Arthroscopic image. Right knee joint. View of complete rupture of the distal stump of anterior cruciate ligament

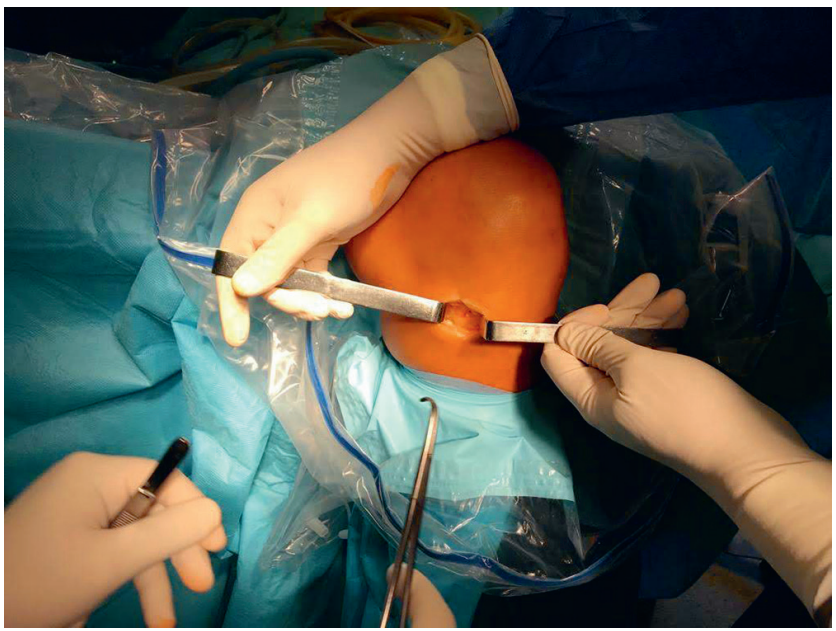

Fig. 2. Intraoperative picture. Left knee joint. Hamstring tendon preparations

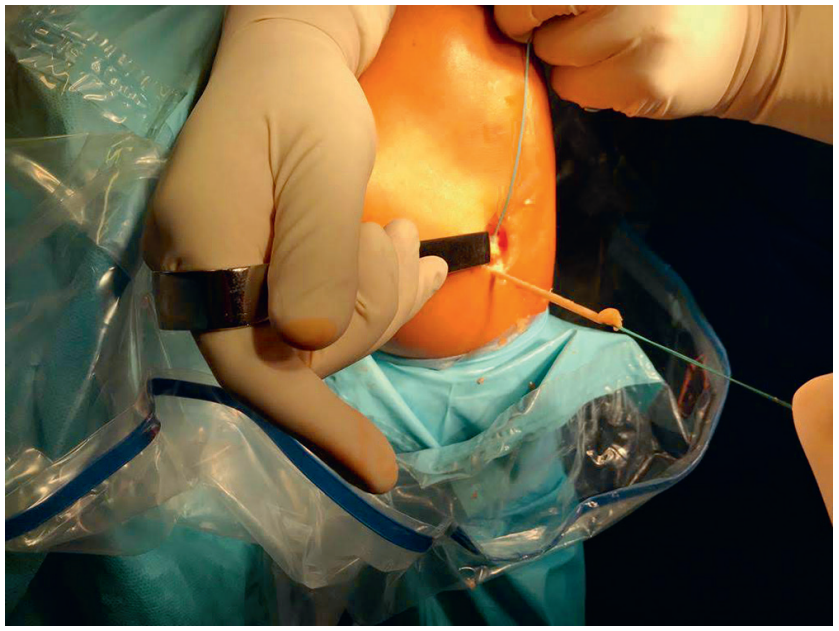

Fig. 3. Intraoperative picture. Left knee joint. Isolated tendon, cut off from distal insertion

guide pin was placed at the center of the ACL footprint using an ACL guide set at about $65^{\circ}$ to the tibial plateau on the sagittal plane (Fig. 6). Then, the guide pin was then over-reamed with a drill. In the next step, a guide pin was drilled from the isometric point across the femur and out the lateral thigh. The autograft/allograft was inserted

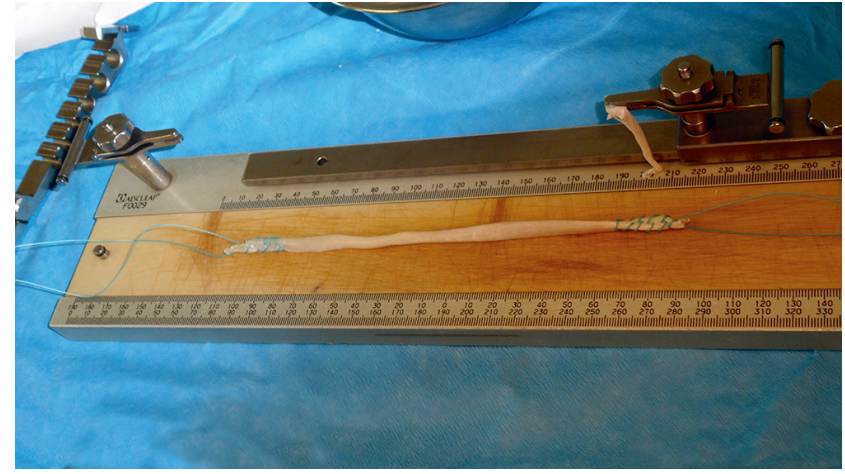

Fig. 4. Cleaned hamstring tendons

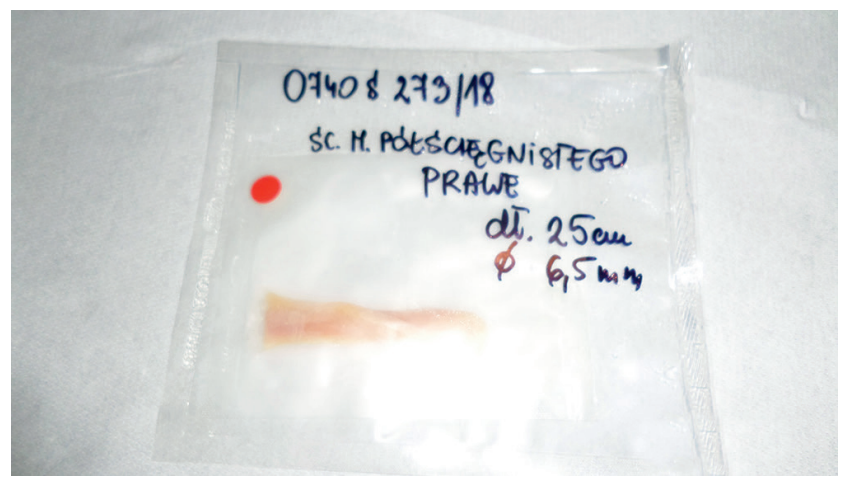

Fig. 5. Freezer allograft from Achilles tendon

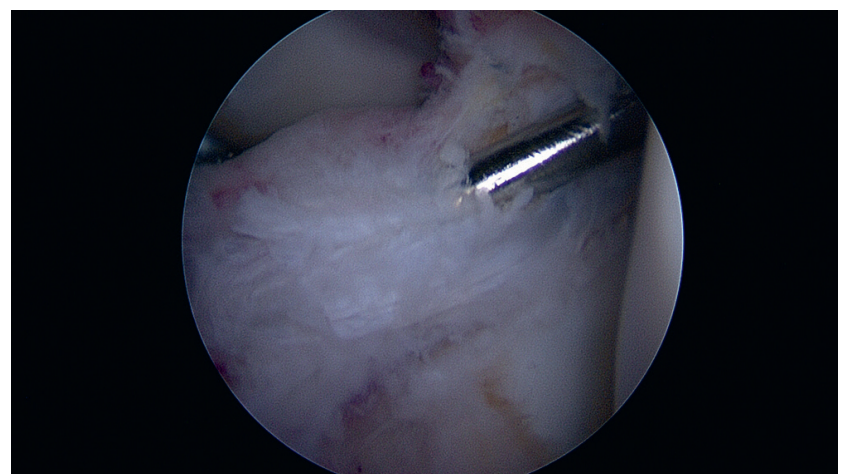

Fig. 6. Arthroscopic image. Left knee joint. K-wire coming out of the tibial footprint

through the tunnels and fixed on the femoral side with an interference screw and tensioned (Fig. 7,8). Fixation on the tibial side was performed using an interference screw at $20^{\circ}$ of flexion with a posterior drawer force applied to the tibia.

\section{Choosing the type of transplant by the patient}

After qualifying the patient for surgical treatment based on the above criteria and their consent to this method of treatment, the choice of graft was discussed with the patient. The final decision with regard to the graft was made by the patient after the operating physician presented 


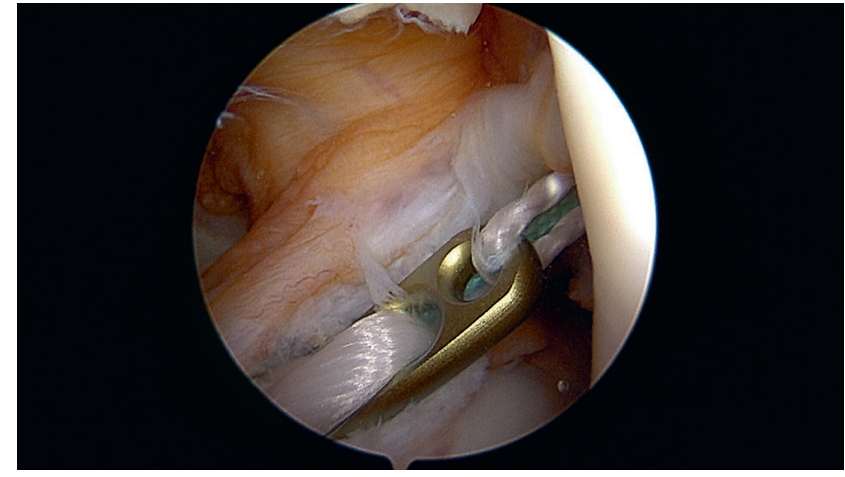

Fig. 7. Arthroscopic image. Left knee joint. View of the Endobutton and loop pull graft into the femoral canal

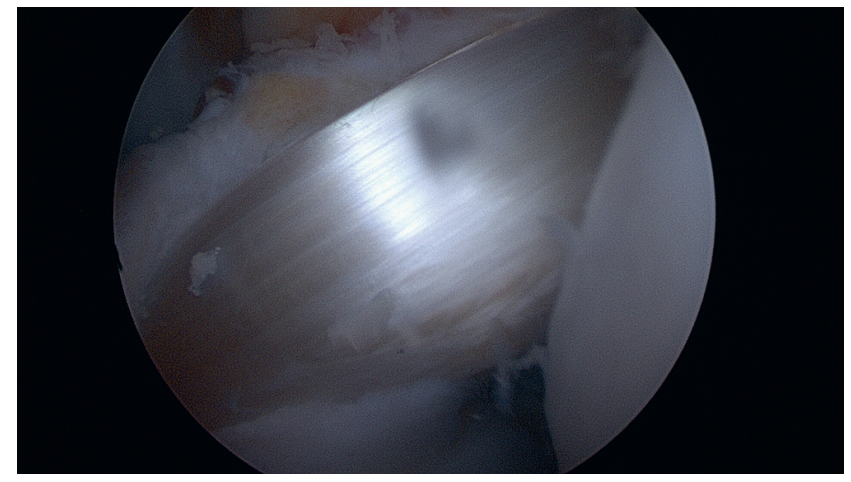

Fig. 8. Arthroscopic image. Left knee joint. View of fixed allograft

the available options along with their advantages and disadvantages. The graft was attached using a Smith-Nephew Endobutton (Smith \& Nephew, Warsaw, USA) on the femoral and the Biomet ComposiTCP30 (Zimmer Biomet, Warsaw, USA) interference screw was placed in the tibia.

\section{Evaluation methods}

The first limb evaluated was a non-traumatic limb in order to assess its range of motion and stability, and to familiarize the patient with the examination technique.

Postoperative control examination took place on days 7, 14 and 28 after surgery. Stitches were removed during examination (in the case of reconstruction using the allograft usually on day 7 , in the case of autografts on day 14). Stress relief and the use of orthosis were recommended for a period of 3 weeks, increasing the range of flexion in the orthosis in a $30^{\circ}-60^{\circ}-90^{\circ}$ schedule every 7 days. The active range of motion (ROM) of the knee was measured bilaterally using a standard goniometer. ${ }^{10}$ Anterior knee stability was evaluated manually using the Lachman test and anterior drawer test, in accordance with the ligament examination section of the 2000 International Knee Documentation Committee (IKDC). ${ }^{11}$ The inter-limb difference in anterior tibial dislocation obtained from the Lachman test and anterior drawer test was rated as normal $(0 ; 0-2 \mathrm{~mm})$, nearly normal (1+;3-5 mm), abnormal (2+;6-10 mm), or severely abnormal $(3+;>10 \mathrm{~mm}) .{ }^{11}$ Anterolateral rotational knee stability was assessed manually with the Pivot-Shift test. The Pivot-Shift test was considered negative when, according to the ligament examination section of the 2000 IKDC, the anterolateral rotational dislocation of the tibia relative to the femur was equal in both lower limbs and positive when the difference between the limbs was rated as + (glide) ++ (clunk) or +++ (gross).

\section{Statistical analysis}

Statistical analysis was performed using the TIBCO Statistica $^{\mathrm{TM}}$ program (TIBCO Software Inc., Palo Alto, USA) and Microsoft Office Excel 365 Personal (Microsoft Corporation, Redmond, USA).

In the case of the characteristics of the tested material and analysis of the so-called feelings of "giving-way", Lachman test, anterior drawer and Pivot-Shift test results, and in the analysis of postoperative complications, the number of patients ( $\mathrm{n}$ ) who obtained a given result in particular examined groups were determined. The percentage of the study group in which patients who obtained a given result was calculated through a comparison of the results between the study groups.

The arithmetic mean ( $\mathrm{x}$ ) and \pm standard deviation (SD) were calculated for the following parameters tested: active range of extension and flexion in the operated and non-operated limb $\left[^{\circ}\right]$, total number of points obtained on the Lysholm scale in the operated limb (n points) and total number of points obtained in the IKDC 2000 (n points). The Shapiro-Wilk test was performed to examine the normality of the distribution of the analyzed parameters. In the comparison of the values of the active range of extension and flexion obtained in the operated and non-operated limb, a parametric t-test was used for dependent groups. In comparison, within the same group, of the values of the active range of extension and flexion in the operated and non-operated limb scale obtained at particular intervals, a one-way analysis of variance (ANOVA) variance analysis was used followed by Tukey's post hoc test. To compare the examined groups, the values of the active range of extension and flexion in the operated and non-operated limb, the number of points obtained on the Lysholm scale in the operated limb and the number of points obtained in the IKDC 2000 at the same intervals parametric t-test for independent groups was used.

\section{Results}

\section{Clinical evaluation results}

Comparison of clinical tests in individual groups confirming clinical status before surgery is shown in Fig. 9. The results of knee "giving way", the Lachman test, anterior drawer test, and Pivot-Shift test were negative in all cases after operation, meaning the knee was stable in both groups 


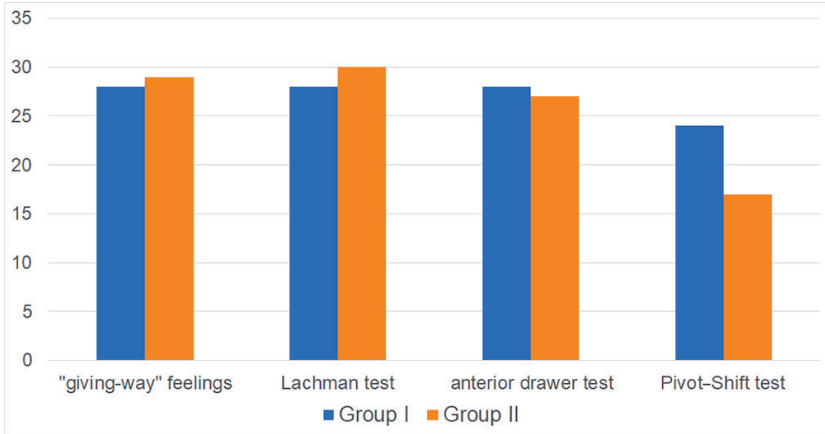

Fig. 9. Comparison of the results of "giving-way", Lachman test, anterior drawer test, and Pivot-Shift test in Group I and II before surgery index

in all cases. Statistically significant results were found in all tests comparing preoperative examination with examinations after 3, 6 and 18 months after surgery. No statistically significant differences were found when comparing results in an intergroup of 3, 6 and 18 months after reconstruction and in intergroups in identical study periods.

In Group I, the ROM of active knee extension before ACL reconstruction was statistically significantly lower $(\mathrm{p}=0.005)$ in the operated $\operatorname{limb}\left(\mathrm{x}=1.61 \pm 3.00^{\circ}\right)$ compared to the non-operated $\operatorname{limb}\left(x=0.00 \pm 0.00^{\circ}\right)$. In the comparison of the obtained active extension range values in the operated limb in Group I, it was noted that there was a statistically significant difference in subsequent measurements $(\mathrm{p} \leq 0.001)$ (Table 1).

In Group I, before surgery, the ROM of the active knee flexion in the operated $\operatorname{limb}\left(x=113.23 \pm 8.32^{\circ}\right)$ was statistically significantly smaller $(\mathrm{p}=0.001)$ than in the non-operated $\operatorname{limb}\left(\mathrm{x}=134.19 \pm 3.19^{\circ}\right)$ as well as at $3(\mathrm{p} \leq 0.001)$ and 6 ( $\mathrm{p} \leq 0.001)$ months after reconstruction. Also, the ROM in the $18^{\text {th }}$ month after reconstruction was statistically significantly lower $(\mathrm{p}=0.031)$ than in the non-operated limb.
However, such a small difference in obtained values should not be regarded as being of clinical significance (Table 1).

In Group II before ACL reconstruction, the ROM of active extension in the operated $\operatorname{limb}\left(x=2.07 \pm 3.08^{\circ}\right)$ was statistically significantly lower $(\mathrm{p} \leq 0.001)$ than in the nonoperated limb $\left(x=0.00 \pm 0.00^{\circ}\right)$. In the studies, ROM was comparable to the non-operated limb within 3, 6 and 18 months after surgery (Table 1 ).

In Group II before ACL reconstruction, the ROM of active flexion in the operated limb $\left(x=111.33 \pm 10.82^{\circ}\right)$ was statistically significantly lower $(\mathrm{p} \leq 0.001)$ than in the non-operated $\operatorname{limb}\left(x=132.83 \pm 2.84^{\circ}\right)$; similarly, within 3 and 6 months after the operation, there were no statistically significant differences ( $p=0.129$ ) only after 18 months (Table 1 ).

The range of active extension movement in the operated limb in Group I statistically significantly increased in the $3^{\text {rd }}$ month from the reconstruction of the ACL compared to the result obtained before the surgery ( $\mathrm{p} \leq 0.001$ ). Between 3 and 6 months after surgery, the range of extension movement did not change statistically ( $p=0.998)$. There were no statistically significant differences between 6 and 18 months after surgery ( $\mathrm{p}=1.000)$ (Table 2).

The ROM of active flexion in the operated limb in Group I demonstrated a statistically significant increase in the $3^{\text {rd }}$ month after reconstruction of the ACL, compared to the result obtained before the surgery $(\mathrm{p} \leq 0.001)$, and similarly, between 3 and 6 months $(\mathrm{p} \leq 0.001)$ and between 6 and 18 months ( $\mathrm{p}=0.012)$ (Table 2).

The ROM of active extension in the operated limb in Group II was statistically significantly larger ( $\mathrm{p}=0.003)$ within 3 months after ACL reconstruction compared to the ROM before reconstruction. There were no significant changes in the operated limb from 3 months to 18 months after surgery (Table 2 ).

Table 1. Comparative analysis values of the measurement of the active flexion and extension in the operated and non-operated limb in Group I and II before reconstruction of the $\mathrm{ACL}$ and 3,6 and 18 months after surgery

\begin{tabular}{|c|c|c|c|c|c|c|}
\hline \multirow{2}{*}{ Variable } & \multicolumn{3}{|c|}{ Group I } & \multicolumn{3}{|c|}{ Group II } \\
\hline & operated limb & non-operated limb & $p$-value & operated limb & non-operated limb & p-value \\
\hline \multicolumn{7}{|c|}{ Extension $\left[{ }^{\circ}\right]$} \\
\hline Before surgery & $1.61 \pm 3.00$ & $0.00 \pm 0.00$ & 0.005 & $2.07 \pm 3.08$ & $0.00 \pm 0.00$ & $\leq 0.001$ \\
\hline 3 months after surgery & $0.45 \pm 1.31$ & $0.00 \pm 0.00$ & 0.065 & $0.40 \pm 1.30$ & $0.00 \pm 0.00$ & 0.103 \\
\hline 6 months after surgery & $0.06 \pm 0.36$ & $0.00 \pm 0.00$ & 0.325 & $0.33 \pm 1.27$ & $0.00 \pm 0.00$ & 0.161 \\
\hline 18 months after surgery & $0.00 \pm 0.00$ & $0.00 \pm 0.00$ & 1.000 & $0.00 \pm 0.00$ & $0.00 \pm 0.00$ & 0.161 \\
\hline$p$-value & $\leq 0.001$ & 1.000 & - & $\leq 0.001$ & 1.000 & - \\
\hline \multicolumn{7}{|c|}{ Flexion $\left[^{\circ}\right]$} \\
\hline Before surgery & $113.23 \pm 8.32$ & $134.19 \pm 3.19$ & $\leq 0.001$ & $111.33 \pm 10.82$ & $132.83 \pm 2.84$ & $\leq 0.001$ \\
\hline 3 months after surgery & $121.94 \pm 10.46$ & $134.19 \pm 3.19$ & $\leq 0.001$ & $114.50 \pm 16.10$ & $132.83 \pm 2.84$ & $\leq 0.001$ \\
\hline 6 months after surgery & $128.55 \pm 5.80$ & $134.19 \pm 3.19$ & $\leq 0.001$ & $126.00 \pm 7.36$ & $132.83 \pm 2.84$ & $\leq 0.001$ \\
\hline 18 months after surgery & $133.23 \pm 4.75$ & $134.19 \pm 3.19$ & 0.031 & $131.67 \pm 5.62$ & $132.83 \pm 2.84$ & 0.129 \\
\hline$p$-value & $\leq 0.001$ & 1.000 & - & $\leq 0.001$ & 1.000 & - \\
\hline
\end{tabular}

Values expressed as the arithmetic mean and \pm SD. 
Table 2. Statistical significance analysis results of the measurement of the active flexion and extension in the operated limb in Group I and II at particular time intervals

\begin{tabular}{|c|c|c|c|c|c|c|c|c|}
\hline \multirow{2}{*}{ Variable } & \multicolumn{2}{|c|}{ Before surgery } & \multicolumn{2}{|c|}{3 months after surgery } & \multicolumn{2}{|c|}{6 months after surgery } & \multicolumn{2}{|c|}{18 months after surgery } \\
\hline & Group I & Group II & Group I & Group II & Group I & Group II & Group I & Group II \\
\hline \multicolumn{9}{|c|}{ Extension } \\
\hline Before surgery & - & - & $\leq 0.001$ & 0.003 & $\leq 0.001$ & 0.002 & $\leq 0.001$ & $\leq 0.001$ \\
\hline 3 months after surgery & $\leq 0.001$ & 0.003 & - & - & 0.998 & 0.999 & 1.000 & 0.941 \\
\hline 6 months after surgery & $\leq 0.001$ & 0.002 & 0.998 & 0.999 & - & - & 0.998 & 0.974 \\
\hline 18 months after surgery & $\leq 0.001$ & $\leq 0.001$ & 1.000 & 0.941 & 0.998 & 0.974 & - & - \\
\hline \multicolumn{9}{|c|}{ Flexion } \\
\hline Before surgery & - & - & $\leq 0.001$ & 0.665 & $\leq 0.001$ & $\leq 0.001$ & $\leq 0.001$ & $\leq 0.001$ \\
\hline 3 months after surgery & $\leq 0.001$ & 0.665 & - & - & $\leq 0.001$ & $\leq 0.001$ & $\leq 0.001$ & $\leq 0.001$ \\
\hline 6 months after surgery & $\leq 0.001$ & $\leq 0.001$ & $\leq 0.001$ & $\leq 0.001$ & - & - & 0.012 & 0.179 \\
\hline 18 months after surgery & $\leq 0.001$ & $\leq 0.001$ & $\leq 0.001$ & $\leq 0.001$ & 0.012 & 0.179 & - & - \\
\hline
\end{tabular}

Values expressed as p (level of statistical significance).

Table 3. The value of anterior tibial translation in the operated limb in individual study groups between measurements and comparison between study groups

\begin{tabular}{|l|c|c|c|}
\hline \multicolumn{4}{|c|}{ Anterior tibial translation [mm] } \\
\hline \multicolumn{1}{|c|}{ Variable } & Group I & Group II & $7.67 \pm 2.55$ \\
\hline Before surgery & $7.30 \pm 2.57$ & $1.65 \pm 0.70$ & 0.571 \\
\hline 3 months after surgery & $1.81 \pm 0.70$ & $1.58 \pm 0.65$ & 0.009 \\
\hline 6 months after surgery & $1.83 \pm 0.66$ & $1.66 \pm 0.74$ & 0.020 \\
\hline 18 months after surgery & $1.79 \pm 0.72$ & $\leq 0.001$ & 0.021 \\
\hline p-value & $\leq 0.001$ & - \\
\hline
\end{tabular}

Values expressed as the arithmetic mean and \pm SD.

Table 4. The results of the comparative analysis of the value of the anterior tibial shift relative to the thigh in the operated limb in Group I and II between individual measurements

\begin{tabular}{|c|c|c|c|c|c|c|c|c|}
\hline \multicolumn{9}{|c|}{ Anterior tibial translation [mm] } \\
\hline \multirow{2}{*}{ Variable } & \multicolumn{2}{|c|}{ before surgery } & \multicolumn{2}{|c|}{3 months after surgery } & \multicolumn{2}{|c|}{6 months after surgery } & \multicolumn{2}{|c|}{18 months after surgery } \\
\hline & Group I & Group II & Group I & Group II & Group I & Group II & Group I & Group II \\
\hline Before surgery & - & - & $\leq 0.001$ & $\leq 0.001$ & $\leq 0.001$ & $\leq 0.001$ & $\leq 0.001$ & $\leq 0.001$ \\
\hline 3 months after surgery & $\leq 0.001$ & $\leq 0.001$ & - & - & 1.000 & 1.000 & 1.000 & 1.000 \\
\hline 6 months after surgery & $\leq 0.001$ & $\leq 0.001$ & 1.000 & 1.000 & - & - & 1.000 & 1.000 \\
\hline 18 months after surgery & $\leq 0.001$ & $\leq 0.001$ & 1.000 & 1.000 & 1.000 & 1.000 & - & - \\
\hline
\end{tabular}

A comparison ROM of flexion in the operated limb in Group II showed a statistically significant difference in the measurements taken ( $\mathrm{p} \leq 0.001)$ (Table 2).

In Group I, the tibial translation in the operated limb was $x=7.30 \pm 2.57 \mathrm{~mm}$. After the ACL reconstruction, the translation statistically significantly decreased and amounted to $\mathrm{x}=1.81 \pm 0.70 \mathrm{~mm}$ when measured 3 months after the ACL reconstruction. In the following months, the anterior displacement of the tibia relative to the thigh was comparable at 6 and 18 months (Table 3).

In Group II, the anterior displacement in the operated limb was $x=7.67 \pm 2.55 \mathrm{~mm}$. After the ACL reconstruction, displacement statistically significantly decreased $1.65+0.70 \mathrm{~mm}$ when measured 3 months after the ACL reconstruction. In the following months, the anterior displacement was comparable at 6 months and at 18 months after reconstruction.

By comparing the results of the tibial translation, statistical significance was demonstrated between surgical and postoperative treatment, while no statistical differences were found when comparing studies in a given research period both in Group I and II (Tables 3 and 4).

\section{Functional assessment results}

Within 18 months of the reconstruction of the ACL, the average total number of points obtained on the Lysholm Group I scale was $96.97 \pm 3.04$ points. In Group II, patients 


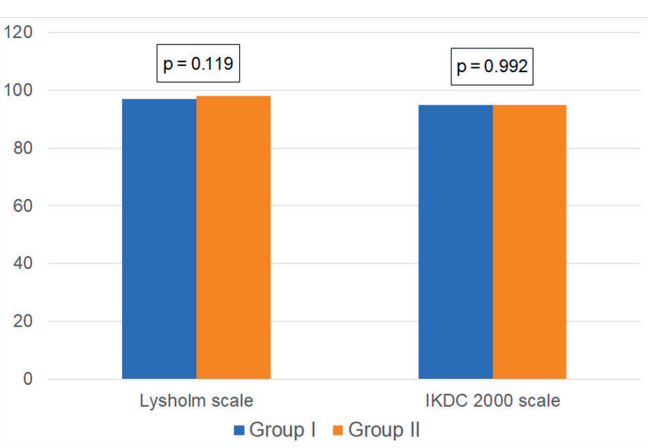

Fig. 10. Comparative analysis of the total number of points on the Lysholm scale and on the IKDC 2000 scale obtained in Group I and Group II

obtained an average of $98.00 \pm 1.91$ points in the same period since surgery (Fig. 10). A comparative analysis of the results of the functional assessment based on the Lysholm scale did not show statistically significant differences $(\mathrm{p}=0.119)$.

Within 18 months of the reconstruction of the ACL, the average total number of points on the IKDC 2000 scale obtained in Group I was $94.79 \pm 6.54$ points. In Group II, patients obtained an average of $94.81 \pm 5.63$ points in the same period since surgery (Fig. 10). A comparative analysis of the results of the functional assessment did not show statistically significant differences between the examined groups $(\mathrm{p}=0.992)$.

\section{Discussion}

Knee injuries are one of the most common injuries experienced during physical activity, resulting in the need for surgical treatment and a prolonged interruption in the ability to play sports. ${ }^{3,4}$

Statistics and numbers demonstrate the scale of the problem. In the USA alone, the number of cruciate ligament injuries is estimated to be at 250,000 per year, and the cost of diagnosis, treatment and rehabilitation is $\$ 3$ trillion. ${ }^{12,13}$ No data could be found regarding the number of reconstructions of the ACL in Poland.

Many reports show different views of the researchers regarding the right time for surgical treatment, selection and method of graft attachment, method of bone canal preparation, or postoperative rehabilitation. ${ }^{10,11,14-22}$

The choice of surgical technique and method of graft attachment is usually the responsibility of the surgeon, depending on their preferences and previous experience. ${ }^{23}$

The choice of graft used as a transplant for reconstruction of the ACL also largely depends on the patient's choice and expectations. However, it should be taken into account that according to statistical studies, $74 \%$ of patients choose the transplant depending on the doctor's recommendation. ${ }^{24}$

Autograft effects described by other researchers ${ }^{25}$ and also observed among patients at the medical center in Wrocław, mainly related to their data collection, sparked the search for an alternative to a transplant autograft. The number of reports regarding the use of allografts in orthopedics is increasing. Up to 5 million allografts were performed in the USA in the last decade. ${ }^{25,26}$

The Achilles tendon and posterior (TP) and anterior (TA) tendons were used for an allograft. However, a small group of patients and a short observation period did not permit a comparison of their treatment results within the research group. Results published by other researchers show comparable results of treatment using allogeneic Achilles, ST, TA, and TP allografts. They also emphasize the fact that this gives greater freedom in the size of allograft. ${ }^{27}$

The average age of patients in the allograft group was 37.8 years, and 30.4 years in the autograft group. This is in line with the observations of other authors that the allograft is more often chosen by patients over 35 years of age who no longer compete in sports. ${ }^{28} \mathrm{~A}$ more recent metaanalysis by Kaeding et al. observed the increase in the average age of patients operated on using the allograft, starting at 30 years of age during the years 2002-2003 to almost 40 years of age during the years 2008-2009, which, however, also significantly correlated with the decrease in graft bursts - from $11.7 \%$ during the years $2002-2003$ to $3.7 \%$ during the years 2008-2009. ${ }^{29}$

The team at the medical center prepared the tibial canal with the outside-in technique, and the femoral canal was drilled with the transtibial technique. The treatment results in both groups show that it is a repeatable and effective surgical technique. This is in line with the observations of other researchers, showing comparatively good treatment results with this method with the technique of drilling through an additional medial portal. ${ }^{30-32} \mathrm{How}-$ ever, other authors have indicated better treatment results in patients whose femoral canal was drilled through the medial portal. ${ }^{33}$ Despite the use of the same surgical technique and the use of the same fixation methods, the average time of surgery in both groups was different. These data show that the selection of the graft for reconstruction had a direct impact on surgery duration. This difference is due to the need to take graft when using autografts. This coincides with the observations of other authors. ${ }^{16,25,34}$ Based on the studies of Ericson et al. and Balasch et al., ${ }^{35,36}$ a Rolimeter was used for the quantitative study of anterior tibial displacement. In our opinion, this examination does not affect the choice of surgical technique, method of attachment or type of graft. It is useful in assessing postoperative improvement in knee stability. It can also be helpful in assessing the patient after re-injury to the knee after ACL reconstruction. The increase in tibial anterior translation after injury compared to the results of post-reconstruction control tests may be evidence of graft damage, which is difficult to assess with MRI.

In both groups, the range of active extension and flexion of the preoperative limb was similar and statistically 
different from the range of the non-operated limb. In both groups, during control tests after 3, 6 and 18 months, statistically significant improvement in the ROM was observed, both in terms of extension and flexion. In the group of allografts and autografts in a study after 18 months, there was a smaller range of flexion of the operated to nonoperated limb, but it was not clinically significant.

Analysis of the knee joint stability assessment using Lachman, front drawer, Pivot-Shift, and Rolimeter tests showed that proper knee joint stability was obtained in both groups. There was no difference in the results obtained between the 2 groups. Similar observations in their meta-analyses were described by Bottoni et al. and Jia et al. ${ }^{37,38}$

Subjective assessment of knee function in patients from both groups was made using the Lysholm scale and IKDC 2000. Comparative analysis did not show significant differences between the results of patients operated on using allografts and the results of patients operated on using autografts. Good subjective postoperative results were shown.

Our method was limited by the lack of biomechanical tests and a short observation period. In the future, our research requires a longer period of observation and analysis of possible issues of re-tearing of the graft and weakening of the flexor strength of the operated limb after primary reconstruction of ACL using hamstrings.

Today, many studies are underway to highlight genetic predisposition to cruciate ligament injuries. The ACL "suture" techniques require further research and more material. Research on the use of scaffolds, stem cells, platelet rich plasma, and xenografts are also setting new trends. All these current trends in the development of ACL surgery will allow for a more personalized method of surgical treatment, which will probably be presented to the patient as the choice of "à la carte" method of treatment.

\section{Conclusions}

Primary ACL reconstruction using an allograft is an effective method to treat instability of the anterior knee joint. Comparative analysis of the results of primary ACL reconstruction in the treatment of anterior knee instability using autograft and allograft justifies the possibility of individual selection of the graft depending on the patient's expectations.

\section{ORCID iDs}

Sebastian Krupa (1) https://orcid.org/0000-0002-3952-8123

Paweł Reichert (1) https://orcid.org/0000-0002-0271-4950

\section{References}

1. Ekstrand J. A 94\% return to elite level football after ACL surgery: A proof of possibilities with optimal caretaking or a sign of knee abuse? Knee Surg Sports Traumatol Arthrosc. 2011;19(1):1-2. doi:10. 1007/s00167-010-1300-4
2. Czamara A, Królikowska A, Szuba Ł, Widuchowski W, Kentel M. Singlevs double-bundle anterior cruciate ligament reconstruction: A new aspect of knee assessment during activities involving dynamic knee rotation. J Strength Cond Res. 2015;29(2):489-499. doi:10.1519/JSC.000 0000000000638

3. Królikowska A, Sikorski $Ł$, Czamara A, Reichert P. Effects of postoperative physiotherapy supervision duration on clinical outcome, speed, and agility in males 8 months after anterior cruciate ligament reconstruction. Med Sci Monit. 2018;24:6823-6831. doi:10.12659/MSM. 912162

4. Cohen SB, Sekiya JK. Allograft safety in anterior cruciate ligament reconstruction. Clin Sports Med. 2007;26(4):597-605.

5. West RV, Harner CD. Graft selection in anterior cruciate ligament reconstruction. J Am Acad Orthop Surg. 2005;13(3):197-207.

6. Zeng C, Gao SG, Li H, et al. Autograft versus allograft in anterior cruciate ligament reconstruction: A meta-analysis of randomized controlled trials and systematic review of overlapping systematic reviews. Arthroscopy. 2016;32(1):153-163.e18. doi:10.1016/j.arthro. 2015.07.027

7. Samuelsson K, Andersson D, Ahldén M, Fu FH, Musahl V, Karlsson J. Trends in surgeon preferences on anterior cruciate ligament reconstructive techniques. Clin Sports Med. 2013;32(1):111-126. doi:10.1016/j. csm.2012.08.011

8. Czamara A, Markowska I, Królikowska A, Szopa A, DomagalskaSzopa M. Kinematics of rotation in joints of the lower limbs and pelvis during gait: Early results-SB ACLR approach versus DB ACLR approach. Biomed Res Int. 2015;2015:707168. doi:10.1155/2015/707168

9. Królikowska A, Czamara A, Kentel M. Does gracilis tendon harvest during ACL reconstruction with a hamstring autograft affect torque of muscles responsible for shin rotation? Med Sci Monit. 2015;21:2084-2093. doi:10.12659/MSM.893930

10. Królikowska A, Czamara A, Szuba $\measuredangle$, Reichert P. The effect of longer versus shorter duration of supervised physiotherapy after $A C L$ reconstruction on the vertical jump landing limb symmetry. Biomed Res Int. 2018;4:7519467

11. Magarian EM, Fleming BC, Harrison SL, Mastrangelo AN, Badger GJ, Murray MM. Delay of 2 or 6 weeks adversely affects the functional outcome of augmented primary repair of the porcine anterior cruciate ligament. Am J Sports Med. 2010;38(12):2528-2534. doi:10.1177/ 0363546510377416

12. Griffin LY, Albohm MJ, Arendt EA, et al. Understanding and preventing noncontact anterior cruciate ligament injuries: A review of the Hunt Valley II meeting, January 2005. Am J Sports Med. 2006; 34(9):1512-1532.

13. Brophy RH, Wright RW, Matava MJ. Cost analysis of converting from single-bundle to double-bundle anterior cruciate ligament reconstruction. Am J Sports Med. 2009;37(4):683-687. doi:10.1177/03635 46508328121

14. Bieri KS, Scholz SM, Kohl S, Aghayev E, Staub LP. Dynamic intraligamentary stabilization versus conventional $A C L$ reconstruction: A matched study on return to work. Injury. 2017;48(6):1243-1248. doi:10.1016/j.injury.2017.03.004

15. Larsson S, Struglics A, Lohmander LS, Frobell R. Surgical reconstruction of ruptured anterior cruciate ligament prolongs trauma-induced increase of inflammatory cytokines in synovial fluid: An exploratory analysis in the KANON trial. Osteoarthritis Cartilage. 2017;25(9): 1443-1451. doi:10.1016/j.joca.2017.05.009

16. Brown MJ, Carter T. ACL Allograft: Advantages and when to use. Sports Med Arthrosc Rev. 2018;26(2):75-78. doi:10.1097/JSA.0000000 000000194

17. Chen H, Chen B, Tie K, Fu Z, Chen L. Single-bundle versus double-bundle autologous anterior cruciate ligament reconstruction: A meta-analysis of randomized controlled trials at 5-year minimum follow-up. J Orthop Surg Res. 2018;13(1):50. doi:10.1186/s13018-0180753-x

18. Speziali A, Delcogliano M, Tei M, et al. Fixation techniques for the anterior cruciate ligament reconstruction: Early follow-up: A systematic review of level I and II therapeutic studies. Musculoskelet Surg. 2014;98(3):179-187. doi:10.1007/s12306-014-0338-8

19. Debieux $P$, Franciozi $C E$, Lenza $M$, et al. Bioabsorbable versus metallic interference screws for graft fixation in anterior cruciate ligament reconstruction. Cochrane Database Syst Rev. 2016;7:CD009772. doi:10.1002/14651858.CD009772.pub2 
20. Jiang H, Ma G, Li Q, Hu Y, Li J, Tang X. Cortical button versus cross-pin femoral fixation for hamstring anterior cruciate ligament reconstruction: A meta-analysis of randomized controlled trials. Am J Sports Med. 2018;46(9):2277-2284. doi:10.1177/0363546517717672

21. Sarzaeem MM, Najafi F, Razi M, Najafi MA. ACL reconstruction using bone-patella tendon-bone autograft: Press-fit technique vs interference screw fixation. Arch Orthop Trauma Surg. 2014;134(7):955-962. doi:10.1007/s00402-014-1999-3

22. Królikowska A, Sikorski Ł, Czamara A, Reichert P. Are the knee extensor and flexor muscles isokinetic parameters affected by the duration of postoperative physiotherapy supervision in patients eight months after ACL reconstruction with the use of semitendinosus and gracilis tendons autograft? Acta Bioengi Biomech. 2018;20(3):89-100.

23. Anderson MJ, Browning WM III, Urband CE, Kluczynski MA, Bisson LJ. A systematic summary of systematic reviews on the topic of the anterior cruciate ligament. Orthop J Sports Med. 2016;4(3): 2325967116634074. doi:10.1177/2325967116634074

24. Cohen SB, Yucha DT, Ciccotti MC, Goldstein DT, Ciccotti MA, Ciccotti MG Factors affecting patient selection of graft type in anterior cruciate ligament reconstruction. Arthroscopy. 2009;25(9):1006-1010. doi:10. 1016/j.arthro.2009.02.010

25. Giedraitis A, Arnoczky SP, Bedi A. Allografts in soft tissue reconstruc tive procedures: Important considerations. Sports Health. 2014;6(3): 256-264. doi:10.1177/1941738113503442

26. de Girolamo L, Ragni E, Cucchiarini M, van Bergen CJA, Hunziker EB, Chubinskaya S. Cells, soluble factors and matrix harmonically play the concert of allograft integration. Knee Surg Sports Traumatol Arthrosc. 2019;27(6):1717-1725. doi:10.1007/s00167-018-5182-1

27. Palmer JE, Russell JP, Grieshober J, et al. A biomechanical comparison of allograft tendons for ligament reconstruction. Am J Sports Med. 2017;45(3):701-707. doi:10.1177/0363546516671944

28. Kaeding CC, Aros B, Pedroza A, et al. Allograft versus autograft anterior cruciate ligament reconstruction: Predictors of failure from a MOON prospective longitudinal cohort. Sports Health. 2011;3(1):73-81.

29. Kaeding CC, Pedroza AD, Reinke EK, et al. Change in anterior cruciate ligament graft choice and outcomes over time. Arthroscopy. 2017;33(11):2007-2014. doi:10.1016/j.arthro.2017.06.019
30. Robin BN, Jani SS, Marvil SC, Reid JB, Schillhammer CK, Lubowitz JH Advantages and disadvantages of transtibial, anteromedial portal, and outside-in femoral tunnel drilling in single-bundle anterior cruciate ligament reconstruction: A systematic review. Arthroscopy. 2015;31(7):1412-1417. doi:10.1016/j.arthro.2015.01.018

31. Rezazadeh S, Ettehadi H, Vosoughi AR. Outcome of arthroscopic single-bundle anterior cruciate ligament reconstruction: Anteromedial portal technique versus transtibial drilling technique. Musculoskelet Surg. 2016;100(1):37-41. doi:10.1007/s12306-015-0392-x

32. Musahl V. A modified transtibial technique was similar to an anteromedial portal technique for anterior cruciate ligament reconstruction. J Bone Joint Surg Am. 2015;97(16):1373. doi:10.2106/JBJS.9716. ebo102

33. Chen $\mathrm{H}$, Tie $\mathrm{K}, \mathrm{Qi} Y$, Li B, Chen $\mathrm{B}$, Chen $\mathrm{L}$. Anteromedial versus transtibial technique in single-bundle autologous hamstring $A C L$ reconstruction: A meta-analysis of prospective randomized controlled trials. J Orthop Surg Res. 2017;12(1):167. doi:10.1186/s13018-017-0671-3

34. Kim YK, Ahn JH, Yoo JD. A comparative study of clinical outcomes and second-look arthroscopic findings between remnant-preserving tibialis tendon allograft and hamstring tendon autograft in anterior cruciate ligament reconstruction: Matched-pair design. Clin Orthop Surg. 2017;9(4):424-431. doi:10.4055/cios.2017.9.4.424

35. Ericsson D, Östenberg AH, Andersson E, Alricsson M. Test-retest reliability of repeated knee laxity measurements in the acute phase following a knee trauma using a Rolimeter. J Exerc Rehabil. 2017;13(5): 550-558. doi:10.12965/jer.1735104.552

36. Balasch $\mathrm{H}$, Schiller M, Friebel H, Hoffmann F. Evaluation of anterior knee joint instability with the Rolimeter: A test in comparison with manual assessment and measuring with the KT-1000 arthrometer. Knee Surg Sports Traumatol Arthrosc. 1999;7(4):204-208.

37. Bottoni CR, Smith EL, Shaha J, et al. Autograft versus allograft anterior cruciate ligament reconstruction: A prospective, randomized clinical study with a minimum 10-year follow-up. Am J Sports Med. 2015;43(10):2501-2509. doi:10.1177/0363546515596406

38. Jia Y, Sun P. Comparison of clinical outcome of autograft and allograft reconstruction for anterior cruciate ligament tears. Chin Med J (Engl). 2015;128(23):3163-3166. doi:10.4103/0366-6999.170265 